\title{
An estimate of dietary exposure of acrylamide in Saudi infants
}

\author{
M. A. Thaiban, M. J. Holmes, C. Orfila and L. J. Marshall \\ School of Food Science and Nutrition, University of Leeds, LS2 9JT, UK
}

Since its discovery in starch-rich processed foods in $2002^{(1)}$, acrylamide, a potential carcinogen, has been widely studied both in terms of toxicity and human exposure. Using concentration data from the UK, Norway, Sweden, Switzerland and the USA, the FAO and WHO estimated the dietary intake (micrograms per kilogram bodyweight per day) for the general population to be in the range of 0.3 to $0.8 \mu \mathrm{g} / \mathrm{kg} \mathrm{bw} / \mathrm{d}^{(2)}$ but, for children, due to lower bodyweight, the intake estimate would generally be 2 to 3 times that of adults. However, there remains a paucity of exposure estimates for other population groups including infants. In this study, 3-day 24-hour records $(n=150)$ from healthy Saudi infants aged 4 to 24 months (separated into age differentiated groups 4-6, 7-9, 10-12, 13-16, 17-24 months) were used to estimate the dietary exposure of acrylamide ${ }^{(3)}$ using concentration data for various food groups from published studies and in particular, we included the contribution from infant milk sources. Based upon minimum, mean and maximum acrylamide concentration levels measured in 17 foods from 34 found from the survey, the mean exposure was estimated to be $5.5 \mu \mathrm{g} / \mathrm{kg}$ bw/d [0.44, 6.22] with the $98^{\text {th }}$ percentile to be 24.62 [6.48, 42.06 low and high respectively] $\mu \mathrm{g} / \mathrm{kg}$ bw/d. The WHO and FAO ${ }^{(2)}$ estimated the average consumption of acrylamide in infants between $6.0 \mu \mathrm{g} / \mathrm{kg}$ bw/d for the $98^{\text {th }}$ percentile consumer, four times lower than the Saudi infant exposure estimate in this research. In the early age groups (4-6 and 7-9 months) acrylamide exposure is primarily associated with increased consumption of bottled milk and cooked vegetables, with $30.92 \%$ and $67.46 \%$ contribution of the total exposure. In contrast in the older groups (10-24 months) the primary exposure is associated with rolled bread and biscuits. In addition, across all age groups there was no significant difference between the mean exposures between female and males with average 5.5 [6.1 and 5.2] $\mu \mathrm{g} / \mathrm{kg}$ bw/d respectively. This work will be extended to include comparative estimates with the 1992 NDNS (National Dietary Nutrition Survey) UK infant study No. 3481.

1. Tareke E, Rydberg P, Karlsson P, Eriksson S, Törnqvist M (2002) Analysis of Acrylamide, a Carcinogen Formed in Heated Foodstuffs. Journal of Agricultural and Food Chemistry 50(17): 4998-5006.

2. FAO/WHO. Health implications of acrylamide in food. Geneva: Issued by the World Health Organization and Food and Agriculture Organization of the United Nations, 2002.

3. Al-Theeban M. Assessment of Nutrition Status for Infants (4-24) Month In Jeddah. Jeddah: King Abdul Aziz University; 2006. 